\title{
High Resolution Investigation of Some Infrared Bands of Carbon Disulfide
}

\author{
Delia Agar, ${ }^{1}$ Earle K. Plyler, and E. D. Tidwell
}

(February 20, 1962)

\begin{abstract}
Absorption bands of carbon disulfide have been measured with high resolution in the regions of 2180 and $2900 \mathrm{~cm}^{-1}$. Bands have been observed due to several isotopic species. By combining the observed bands with those previously measured, a set of harmonicity constants for ${ }^{12} \mathrm{C}^{32} \mathrm{~S}_{2}$ has been obtained in $\mathrm{cm}^{-1}$ as follows: $\mathrm{X}_{11},-1.070 ; \mathrm{X}_{22}, 0.126 ; \mathrm{X}_{33}$, $-6.54 ; \mathrm{X}_{12}, 0.860 ; \mathrm{X}_{13},-7.86 ; \mathrm{X}_{23},-6.45 ; \mathrm{g}_{22}, 0.656$
\end{abstract}

\section{Introduction}

The vibrational spectrum of carbon disulfide has already been extensively studied; the most recent work (in which earlier references are listed) is that of Stoicheff $[1]^{2}$ on the gaseous Raman spectrum, Schrotter [2] on the liquid Raman spectrum, and the infrared investigations by Allen, Plyler, and Blaine [3], Guenther, Wiggins 1 and Rank [4], and Guenther [5].

The spectra of $\mathrm{CS}_{2}$ are of interest because (a) it is possible to observe the frequencies due to several isotopic species $\left[{ }^{12} \mathrm{C}^{32} \mathrm{~S}_{2}, \sim 90 \% ;{ }^{12} \mathrm{C}^{32} \mathrm{~S}^{34} \mathrm{~S}, \sim 8 \%\right.$; ${ }^{13} \mathrm{C}^{32} \mathrm{~S}_{2} \sim 1 \%$; (b) with sufficiently high resolution the $l$-type splitting in the $\pi-\pi$ bands can be obtained; in the symmetrical isotopic species alternate lines of the $\pi^{+}\left(\pi_{c}\right)$ and $\pi^{-}\left(\pi_{d}\right)$ subbands are missing; the consequent staggering of the rotational lines can be measured, though the actual separation of the doublets (such as would occur in the nonsymmetrical species) would need much greater resolving power; this gives an experimental value of the splitting constant $q_{H}$; (c) Fermi resonance occurs between levels such as 100 and $02^{\circ} 0$; from the experimental data some information about the positions of the unperturbed levels and the value of the interaction energy can be estimated.

The main purpose of the present work is to study a number of $\pi-\pi$ bands and their $l$-type splitting. The three combination bands of ${ }^{12} \mathrm{C}^{32} \mathrm{~S}_{2}, \quad \nu_{1}+\nu_{3}$, $2 \nu_{1}+\nu_{3}$, and $\nu_{1}+2 \nu_{2}^{0}+\nu_{3}$, previously analyzed (see ref. [3]) were reinvestigated and their assignments checked, as there had been some criticism (see ref. [1]) of the derived rotational constants. The corresponding hot bands $11^{1} 1-01^{1} 0,21^{1} 1-01^{1} 0$, and $13^{1} 1-$ $01^{1} 0$ were identified and analyzed, and gave values of the splitting constant $q_{H}$ and the rotational

1 Present address, Newnham College, Cambridge, England.

${ }^{2}$ Figures in brackets indicate the literature references at the end of this paper. constant $\alpha_{i}$. One very weak band due to ${ }^{13} \mathrm{C}^{32} \mathrm{~S}_{2}$ was also successfully investigated.

Using the previously published work and the present analyses together with some unpublished results kindly provided by Dr. G. R. Wilkinson [6], it was possible to calculate a complete set of anharmonic constants which appear to be more reliable than those already available. There are now sufficient data to provide some checks on their values corrected for Fermi resonance.

\section{Experimental Method}

The infrared spectrum of $\mathrm{CS}_{2}$ was measured in two regions by the use of a high resolution grating spectrometer [7]. Precise values of the positions of the individual lines were obtained by using the fringe system of a Fabry-Perot interferometer for calibration [8].

A sample of reagent grade carbon disulfide was obtained from the Allied Chemical and Dye Corporation. The only impurity observed in the infrared spectrum was a band of low intensity at $2062 \mathrm{~cm}^{-1}$ which, by its spacing and position, was identified as OCS. However, no lines were observed in the two regions studied which could not be attributed to $\mathrm{CS}_{2}$.

The region from 2165 to $2200 \mathrm{~cm}^{-1}$ was measured with a 7500 lines/in. grating used single pass, and a cooled lead selenide cell was used as the detector. For the region from 2165 to $2200 \mathrm{~cm}^{-1}$, as shown in figure 1 , a $6 \mathrm{~m}$ cell was used with a pressure of the $\mathrm{CS}_{2}$ gas of $3 \mathrm{~mm}(\mathrm{Hg})$.

In the regions from 2784 to 2845 and 2940 to $2980 \mathrm{~cm}^{-1}$ the measurement of the spectrum was obtained with a 10,000 lines/in. grating used double pass. The detector was a cooled lead sulfide cell and a resolution of about $0.03 \mathrm{~cm}^{-1}$ was obtained. A 6 $\mathrm{m}$ cell was used with a gas pressure of $\mathrm{CS}_{2}$ of $25 \mathrm{~mm}$ $(\mathrm{Hg})$. An example of the spectrum in this region is shown in figure 2. 


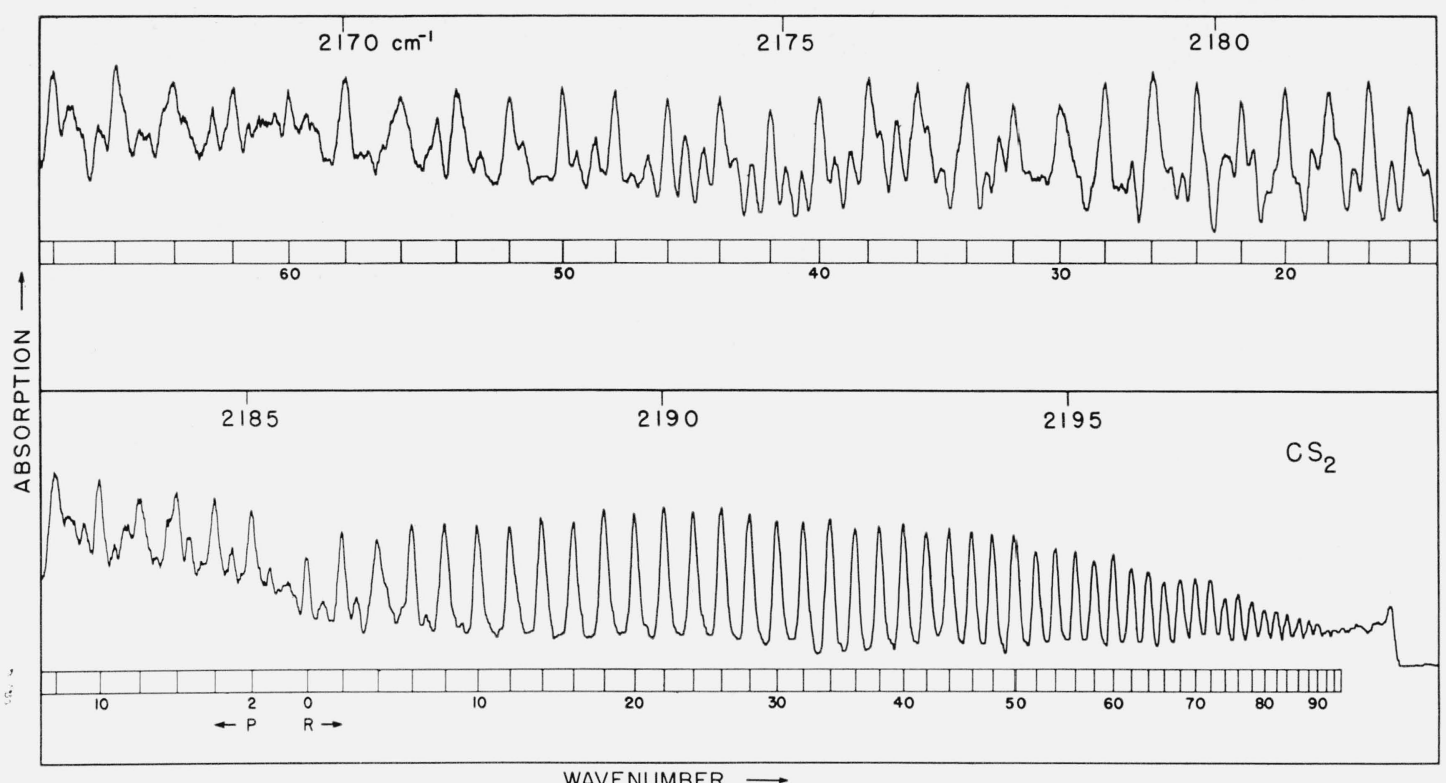

WAVENUMBER $\longrightarrow$

Figure 1. The $\nu_{1}+\nu_{3}$ band of $\mathrm{CS}_{2}$ and the corresponding hot band.

The cell length was $6 \mathrm{~m}$ and the gas pressure was $3 \mathrm{~mm}(\mathrm{Hg})$.

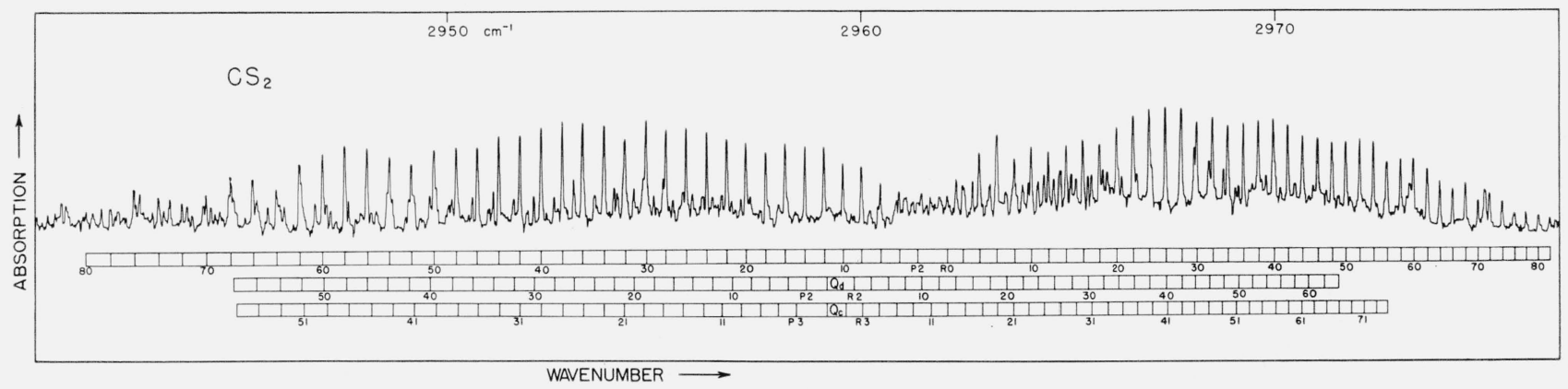

FIGURE 2. The $\nu_{1}+2 \nu_{2}^{0}+\nu_{3}$ band of $\mathrm{CS}_{2}$ with the overlapping hot band $\nu_{1}+3 \nu_{2}^{1}+\nu_{3}-\nu_{2}^{1}$.

The identification of the lines is shown below the spectrum. The cell length was $6 \mathrm{~m}$ and the gas pressure was $25 \mathrm{~mm}(\mathrm{Hg})$.

\section{Determination of Molecular Constants}

In the absence of resonance, the vibrational term values of a linear triatomic molecule (with respect to the lowest vibrational state) are given by the expression:

$$
\begin{aligned}
G_{0}\left[v_{1}, v_{2}, v_{3}\right]=\omega_{1}^{0} v_{1}+\omega_{2}^{0} v_{2}+ & \omega_{3}^{0} v_{3} \\
+X_{11} v_{1}^{2}+X_{22} v_{2}^{2} & +X_{33} v_{3}^{2}+X_{12} v_{1} v_{2} \\
& +X_{23} v_{2} v_{3}+X_{13} v_{1} v_{3}+g_{22} l_{2}^{2}
\end{aligned}
$$

where $l_{2}$ is the quantum number of the vibrational angular momentum about the symmetry axis $\left(l_{2}=\right.$ $v_{2}, v_{2}-2, \ldots 1$ or 0$)$. The rotational energy is given by:

$$
F(J)=[J(J+1)] B_{V}-[J(J+1)] D_{V}
$$

with the condition that $J>l_{2}$. For nondegenerate vibrations the positions of the lines in the $P$ and $R$ branches are represented by the equation:

$$
\begin{array}{r}
\nu=\nu_{0}+\left(B_{V}^{\prime}+B_{V}^{\prime \prime}\right) m+\left(B_{V}^{\prime}-B_{V}^{\prime \prime}\right) m^{2}-\left(D_{V}^{\prime}-D_{V}^{\prime \prime}\right) m^{2} \\
-2\left(D_{V}^{\prime}+D_{V}^{\prime \prime}\right) m^{3}-\left(D_{V}^{\prime}-D_{V}^{\prime \prime}\right) m^{4}
\end{array}
$$

where $m=-J$ for the $P$ branch, and $m=J+1$ for the $R$ branch. From eq (3) the following combination relationships are obtained:

$$
\begin{array}{r}
\Delta_{2} F^{\prime \prime}[J] \equiv R(J-1)-P(J+1) \\
=\left[4 B_{V}^{\prime \prime}-6 D_{V}^{\prime \prime}\right]\left(J+\frac{1}{2}\right)-8 D_{V}^{\prime \prime}\left(J+\frac{1}{2}\right)^{3} \\
R(J)+P(J)=2 \nu_{0}+\left[2 B_{V}^{\prime}-4 D_{V}^{\prime}\right]+2\left[\left(B_{V}^{\prime}-B_{V}^{\prime \prime}\right)\right. \\
\left.-6 D_{V}^{\prime \prime}\right] J(J+1)-2\left(D_{V}^{\prime}-D_{V}^{\prime \prime}\right) J^{2}(J+1)^{2} \\
\Delta_{2} F^{\prime}(J) \equiv R(J)-P(J)=\left[4 B_{V}^{\prime}\right. \\
\left.\quad-6 D_{V}^{\prime}\right]\left(J+\frac{1}{2}\right)-8 D_{V}^{\prime}\left(J+\frac{1}{2}\right)^{3} .
\end{array}
$$

Previous investigations of $\mathrm{CS}_{2}$ suggest that it is 
reasonable, as a first approximation, to put $D_{V}^{\prime} \sim D_{V}^{\prime \prime} \equiv D_{0}$, eqs (3) to (6) then simplify to:

$$
\begin{gathered}
\nu=\nu_{0}+\left(B_{V}^{\prime}+B_{V}^{\prime \prime}\right) m+\left(B_{V}^{\prime}-B_{V}^{\prime \prime}\right) m^{2}-4 D_{0} m^{3} \\
\Delta_{2} F^{\prime \prime}(J)=B_{V}^{\prime \prime}[4 J+2]-4 D_{0}[2 J+1]\left[J^{2}+J+1\right] \\
R(J)+P(J)=2 \nu_{0}+2 B_{V}^{\prime}+2\left[B_{V}^{\prime}-B_{V}^{\prime \prime}\right] J(J+1) \\
-4 D_{0}\left[3 J^{2}+3 J+1\right] \\
\Delta_{2} F^{\prime \prime}(J)=B_{V}^{\prime}[4 J+2]-4 D_{0}[2 J+1]\left[J^{2}+J+1\right] .
\end{gathered}
$$

For the symmetrical isotopic species ${ }^{12} \mathrm{C}^{32} \mathrm{~S}_{2}$ and ${ }^{13} \mathrm{C}^{32} \mathrm{~S}_{2}$ only (4), (5), and (6) or (8), (9), and (10) can be used, since the levels corresponding to odd $J$-values are unpopulated.

The hot bands analyzed in the present work are all of the $\pi-\pi$ type with $l_{2}=1$ in both the upper and lower states. The rotational levels are split, the l-type doubling, and the resultant absorption corresponds to two subbands which are conventionally labeled $\pi^{+}\left(\pi_{c}\right)$ and $\pi^{-}\left(\pi_{d}\right)$, each of which has its own set of molecular constants. Assuming that the centrifugal distortion constants, $D_{0}$, are the same in both states the lines of either subband are given by the formula:

$$
\begin{aligned}
\nu=\nu_{0}-\left(B_{V}^{\prime}-B_{V}^{\prime \prime}\right)+\left(B_{V}^{\prime}\right. & \left.+B_{V}^{\prime \prime}\right] m \\
& +\left(B_{V}^{\prime}-B_{V}^{\prime \prime}\right) m^{2}-4 D_{0} m^{3}
\end{aligned}
$$

from which the following approximate combination relationships [corresponding to (8), (9), and (10)] are derived:

$$
\begin{aligned}
& \Delta_{2} F^{\prime \prime}(J) \equiv R(J-1)-P(J+1) \\
& =B_{V}^{\prime \prime}[4 J+2]-4 D_{0} J(J+1)(2 J+1) \\
& R(J)+P(J)=2 \nu_{0}+2 B_{V}^{\prime \prime} \\
& +2\left[B_{V}^{\prime}-B_{V}^{\prime \prime}\right] J(J+1)-12 D_{0} J(J+1) \\
& \Delta_{2} F^{\prime}(J) \equiv R(J)-P(J) \\
& =B_{V}^{\prime}[4 J+2]-4 D_{0} J(J+1)(2 J+1) .
\end{aligned}
$$

In the $P$ and $R$ branches the transitions occur between $\pi^{+}\left(\pi_{c}\right)$ or $\pi^{-}\left(\pi_{d}\right)$ levels in both upper and lower states giving the two subbands. The weak $Q$ branch arises from $\pi^{+}\left(\pi_{c}\right)$ (upper) $-\pi^{-}\left(\pi_{d}\right)$ (lower) transitions or vice versa. Rotational lines corresponding to $J<1$ (i.e., $Q(0), R(0)$, and $P(1)$ in the present instance) are absent. For the symmetrical isotopic species (only bands due to ${ }^{12} \mathrm{C}^{32} \mathrm{~S}_{2}$ were analyzed) alternate lines of each subband are missing ( $J$ odd for $\pi^{-}\left(\pi_{d}\right), J$ even for $\left.\pi^{+}\left(\pi_{c}\right)\right)$ giving a characteristic staggering of the lines of the complete band. Were the Q-branch resolvable a similar staggering of the lines would be observed. The resolution available is inadequate to separate the doublets which should be observed for such unsymmetrical species as ${ }^{12} \mathrm{C}^{32} \mathrm{~S}^{34} \mathrm{~S}$.

After analysis of the data by standard methods the value of $B_{e}$ (and hence $r_{e}$ ) can be obtained using the relationship:

$$
B_{V}=B_{e}-\sum \alpha_{i}\left[V_{i}+d_{i} / 2\right]
$$

where $d_{i}$ is the degeneracy.

Each of the rotational constants $\alpha_{i}$ can be considered to be made up from three contributions:

$$
\alpha_{i}=\alpha_{i}{ }^{\text {(harm.) }}+\alpha_{i}{ }^{\text {(anharmon.) }}+\alpha_{i}{ }^{\text {(coriolis) }} .
$$

The relevant formulae for the linear $\mathrm{XY}_{2}$ molecule are conveniently tabulated by Herzberg [9, p. 376].

The $l$-type splitting in a degenerate $\pi$ vibrational state $\left(l_{2}=1\right)$ is given by Nielsen [10]:

so that

$$
\Delta \nu=q_{N}\left(v_{2}+1\right) J(J+1)
$$

$$
\Delta \nu=2 q_{N} J(J+1) \text { when } v_{2}=1 .
$$

Herzberg [11] originally suggested that for such a state:

$$
\begin{gathered}
\Delta \nu=q_{H} J(J+1) \\
q_{H}=2\left[\alpha_{i}{ }^{(\text {harm. })}+\alpha_{i}{ }^{(\text {coriolis })}\right]
\end{gathered}
$$

$q_{H}$ being one half of $q_{N}$ (see ref. [9], p. 377-8). ${ }^{3}$

The general formulas for the $l$-type splittings of the degenerate vibrational states of any linear molecule are summarised by Nielsen. The shifts of the perturbed levels from the unperturbed values of a linear $\mathrm{XY}_{2}$ molecule in a $\pi$ state $\left(l_{2}=1\right)$ with $v_{2}=1$ are:

where

$$
\left.\operatorname{shift} \frac{\pi_{c}^{+}}{\pi_{\bar{d}}^{-}}\right\}= \pm 2 q^{\circ} J(J+1)
$$

$$
q^{\circ}=-B_{e}^{2} / 2 \omega_{2}\left[1+4 \omega_{2}^{2} /\left(\omega_{3}^{2}-\omega_{2}^{2}\right)\right]
$$

(Nielsen, Amat, and Goldsmith [12]); this implies that $\Delta \nu=-4 q^{\circ} J(J+1)=q_{H} J(J+1)$ and the Herzberg $q_{H}$ is:

$$
q_{H}=+2 B_{e}^{2} / \omega_{2}+8 B_{e}^{2} \omega_{2} /\left(\omega_{3}^{2}-\omega_{2}^{2}\right)
$$

in agreement with his original suggestion.

\section{Experimental Results}

Three main regions of absorption of $\mathrm{CS}_{2}$ have been investigated; the results are collected in table 1 which also includes some previously published data on ${ }^{12} \mathrm{C}^{32} \mathrm{~S}_{2}$. In the spectral range 2135 to $2199 \mathrm{~cm}^{-1}$ the band $\nu_{1}+\nu_{3}$ and the corresponding hot band $11^{1} 1-01^{1} 0$ of ${ }^{12} \mathrm{C}^{32} \mathrm{~S}_{2}$ have been identified. Together these account for nearly all the lines observed. Those remaining are weak and may belong to the $\nu_{1}+\nu_{3}$ band of ${ }^{13} \mathrm{C}^{32} \mathrm{~S}_{2}$, which should also fall in this region. The absorption between 2222 to 2266 $\mathrm{cm}^{-1}$ is due to the $2 \nu_{2}^{\circ}+\nu_{3}$ band of ${ }^{13} \mathrm{C}^{32} \mathrm{~S}_{2}$, which was analyzed without difficulty as there is little interference from other bands. The region 2784 to $2845 \mathrm{~cm}^{-1}$ is rather complex; it includes the $2 \nu_{1}+\nu_{3}$ band and the hot band $21^{1} 1-01^{1} 0$ of ${ }^{12} \mathrm{C}^{32} \mathrm{~S}_{2}$, and the $3 \nu_{1}+\nu_{3}-\nu_{1}$ band of ${ }^{12} \mathrm{C}^{32} \mathrm{~S}_{2}$, all of which

${ }^{3}$ The splitting constant $q_{H}$ is given by $\left(B_{V}^{-}-B_{V}^{+}\right) \quad$ [i.e., by $\left(B_{V}^{d}-B_{V}^{c}\right)$ ]; this notation is also used by Guenther et al., and Tidwell, Plyler, and Benedict [13] working with $\mathrm{N}_{2} \mathrm{O}$. 
TABLE 1. Summary of the constants of some infrared bands of carbon disulfide

\begin{tabular}{|c|c|c|c|c|c|c|c|c|c|}
\hline \multicolumn{10}{|c|}{ I. ${ }^{12} \mathrm{C}^{32} \mathrm{~S}_{2}$} \\
\hline Band & $\nu_{0} \mathrm{~cm}^{-1}$ & $B^{\prime \prime} \mathrm{em}^{-1}$ & $\begin{array}{c}B^{\prime}-B^{\prime \prime} \\
\Delta B \mathrm{~cm}^{-1}\end{array}$ & $B^{\prime} \mathrm{cm}^{-1}$ & $D^{\prime \prime} \mathrm{cm}^{-1}$ & $\begin{array}{c}D^{\prime}-D^{\prime \prime} \\
\Delta D \mathrm{~cm}^{-1}\end{array}$ & $D^{\prime} \mathrm{cm}^{-1}$ & $\underset{q_{H}}{B_{V} d^{-}-B_{V} c^{+}}$ & \\
\hline$\nu_{1}+\nu_{3}$ & 2185.492 & 0.10912 & $-8.6_{5} \times 10^{-4}$ & 0.108255 & 1. $38 \times 10^{-8}$ & $\sim 0$ & 1. $38 \times 10^{-8}$ & & (a) \\
\hline $\begin{array}{l}11^{\prime} 1-01^{\prime} 0 \\
\pi^{+} c(\text { odd })\end{array}$ & 2171.42 & .10940 & $-8.58 \times 10^{-4}$ & $.10854_{2}$ & $\sim 2 \times 10^{-8}$ & $\sim 0$ & $\sim 2 \times 10^{-8}$ & $q^{\prime \prime} \sim 1 \times 10^{-4}$ & (a) \\
\hline $\begin{array}{l}11^{\prime} 1-01^{\prime} 0 \\
\pi^{-} d \text { (even) }\end{array}$ & 2171. 42 & .10950 & $-8.4_{5} \times 10^{-4}$ & $.10865_{5}$ & $\sim 2 \times 10^{-8}$ & $\sim 0$ & $\sim 2 \times 10^{-8}$ & $q^{\prime} \sim 1.1_{3} \times 10^{-4}$ & (a) \\
\hline $2 \nu_{1}+\nu_{3}$ & 2833. 191 & .109071 & $\begin{array}{r}-1.003 \times 10^{-3} \\
\pm 2 \times 10^{-6}\end{array}$ & .108068 & $0.8 \times 10^{-8}$ & $+0.118 \times 10^{-8}$ & $0.92 \times 10^{-8}$ & & (a) \\
\hline $\begin{array}{l}21^{\prime} 1-01^{\prime} 0 \\
\pi^{+} c(\text { odd })\end{array}$ & 2811.350 & .10940 & $-8.85 \times 10^{-4}$ & $.10851_{5}$ & $\sim 3 \times 10^{-8}$ & $\sim 0$ & $\sim 3 \times 10^{-8}$ & $g^{\prime \prime} \sim 1 \times 10^{-4}$ & (a) \\
\hline $\begin{array}{l}21^{\prime} 1-01^{\prime} 0 \\
\pi^{-}-d \text { (even) }\end{array}$ & 2811. 350 & .10950 & $-8.75 \times 10^{-4}$ & $.10862_{5}$ & $\sim 3 \times 10^{-8}$ & $\sim 0$ & $\sim 3 \times 10^{-8}$ & $q^{\prime} \sim 1.1 \times 10^{-4}$ & (a) \\
\hline$\nu_{1}+2 \nu_{2}^{0}+\nu_{3}$ & $\begin{array}{l}2961.791 \\
\pm 0.0016\end{array}$ & $\begin{array}{r}.109040 \\
\pm 1 \times 10^{-5}\end{array}$ & $-4.562 \times 10^{-4}$ & .108584 & $\begin{array}{r}0.88 \times 10^{-8} \\
\pm .134 \times 10^{-8}\end{array}$ & $<5 \times 10^{-11}$ & $\begin{array}{r}0.88 \times 10^{-8} \\
\pm .134 \times 10^{-8}\end{array}$ & & (a) \\
\hline $\begin{array}{l}13^{\prime} 1-01^{\prime} 0 \\
\pi^{+} r \text { (odd) }\end{array}$ & 2959.117 & 0.10940 & $-5.2 \times 10^{-4}$ & .10888 & $\sim 4 \times 10^{-8}$ & $\sim 0$ & $\sim 4 \times 10^{-8}$ & $q^{\prime \prime} \sim 1 \times 10^{-4}$ & (a) \\
\hline $\begin{array}{l}13^{\prime} 1-01^{\prime} 0 \\
\pi^{-}-d \text { (even) }\end{array}$ & 2959. 117 & .10950 & $-4.4 \times 10^{-4}$ & .10906 & $\sim 3 \times 10^{-8}$ & $\sim 0$ & $\sim 3 \times 10^{-8}$ & $q^{\prime} \sim 1.8 \times 10^{-4}$ & (a) \\
\hline $3 \nu_{3}$ & 4566.810 & $\begin{array}{c}.109099 \\
\pm 2.3 \times 10^{-5}\end{array}$ & 2. $133 \times 10^{-3}$ & $\begin{array}{r}.106956 \\
\pm 2 \times 10^{-5}\end{array}$ & $\begin{array}{r}\text { 1. } 05 \times 10^{-8} \\
\pm 0.36 \times 10^{-8}\end{array}$ & $+0.03 \times 10^{-8}$ & $\begin{array}{r}\text { 1. } 08 \times 10^{-8} \\
\pm 0.33 \times 10^{-8}\end{array}$ & & (b) \\
\hline $\begin{array}{l}01^{\prime} 3-01^{\prime} 0 \\
\pi^{+} c \text { (odd) }\end{array}$ & 4547.464 & 0.109321 & 2. $126 \times 10^{-3}$ & 0. 107195 & $1.1 \times 10^{-8}$ & $\sim 0$ & $1.1 \times 10^{-8}$ & $q^{\prime \prime}=6.7 \times 10^{-5}$ & (b) \\
\hline $\begin{array}{l}01^{\prime} 3-01^{\prime} 0 \\
\pi^{-}-d \text { (even) }\end{array}$ & 4547.464 & .109388 & 2. $129 \times 10^{-3}$ & .107259 & $1.1 \times 10^{-8}$ & $\sim 0$ & $1.1 \times 10^{-8}$ & $q^{\prime \prime}=6.4 \times 10^{-5}$ & (b) \\
\hline $\begin{array}{l}\text { Pure Rotation } \\
\text { (Raman) }\end{array}$ & & $\begin{array}{l}.10910 \\
\pm 5 \times 10^{-5}\end{array}$ & & & 1. $0 \times 10^{-8}$ & & & & (c) \\
\hline
\end{tabular}

II. ${ }^{13} \mathrm{C}^{32} \mathrm{~S}_{2}$

\begin{tabular}{l|l|l|l|l|l|l|l|l}
\hline $2 \nu_{2}^{0}+\nu_{3}$ & $2250.15_{2}$ & 0.10908 & $-3.48 \times 10^{-4}$ & .10873 & $1.08 \times 10^{-8}$ & $\sim 0$ & $1.08 \times 10^{-8}$ & $\ldots \ldots \ldots$ \\
\hline
\end{tabular}

a Present work.

b A. H. Guenther, T. A. Wiggins, and D. H. Rank, J. Chem. Phys, 28, 682-7 (1958)

- B. P. Stoicheff, Can. J. Phys. 36, 218-230 (1958).

overlap. These account for nearly all the prominent lines, though some weak lines are also observed which were not assigned. The absorption in the region 2931 to $2999 \mathrm{~cm}^{-1}$ corresponds to the $\nu_{1}+2 \nu_{2}^{\circ}+\nu_{3}$ band and the hot band $13^{1} 1-01^{1} 0$ of ${ }^{12} \mathrm{C}^{32} \mathrm{~S}_{2}$, with the band $2 \nu_{1}+2 \nu_{2}+\nu_{3}-\nu_{1}$ of ${ }^{12} \mathrm{C}^{32} \mathrm{~S}_{2}$ at the lower end of the range. Most of the observed lines have been assigned except rather weak ones at lower frequencies.

The data presented in table 1 show that there is reasonable agreement between the values of the ground state constant $R_{000}$ of ${ }^{12} \mathrm{C}^{32} \mathrm{~S}_{2}$ as determined from four infrared bands and the pure rotational Raman spectrum. In particular the values derived from the revised analyses of $\nu_{1}+\nu_{3}, 2 \nu_{1}+\nu_{3}$, and $\nu_{1}+2 \nu_{2}^{\circ}+\nu_{3}$ now fall in line with those of other investigators, though perhaps $0.10904 \mathrm{~cm}^{-1}$ for the latter band is rather small. It appears that 0.10910 $\mathrm{cm}^{-1}$ is a reliable value for $B_{000}$; this makes the C-S distance $r_{0}=1.5545 \mathrm{~A}$ as proposed previously [Guenther et al.]. The calculated value of $D_{000}$ $\left[4 B_{0}^{3} / \omega_{1}^{2}\right]$ is $1.20 \times 10^{-8} \mathrm{~cm}^{-1}$ [Guenther et al., Stoicheff]; the experimental determinations are scattered about this ingure. From these, a value of $D_{000}=1.02 \pm 0.3 \times 10^{-8} \mathrm{~cm}^{-1}$ would seem probable.

The situation is less satisfactory for the $01^{1} 0$ levels, which have also been observed in four different bands. The present results (three bands) are con- sistent among themselves [though the $B^{\prime \prime}$ values from the $21^{1} 1-01^{1} 0$, and $13^{1} 1-01^{1} 0$ bands were used effectively to analyze the $11^{1} 1-01^{1} 0$ band, for which the experimental data were less precise], but they are larger than those derived from the $01^{1} 3-01^{1} 0$ band by Guenther et al., and these constants are probably not so accurate. Further, the results obtained for $D_{000}$ in the present analyses are somewhat larger than would be expected.

The present values of the splitting constants $q_{H}^{\prime \prime}$ and $q_{H}^{\prime}$ are all about $1 \times 10^{-4} \mathrm{~cm}^{-1}$ for levels in which $l_{2}=v_{2}=1$. This is of the right order of magnitude, the calculated value being $q_{H}=7.74 \times 10^{-5} \mathrm{~cm}^{-1}$ (using $v_{3}=1535.35 \mathrm{~cm}^{-1}$ ) and those previously published being 6.4 and $6.7 \times 10^{-5} \mathrm{~cm}^{-1}$ (Guenther et al.). The theoretical treatment suggests that all $\pi$ states $\left(l_{2}=1\right)$ with $\nu_{2}=1$ should have the same $q_{H}$ and this appears to be the case. The only other level observed $\left(13^{1} 1\right)$ has a larger value for this constant. It is about twice as large as the $q \mathrm{H}$ for a $v_{2}=1$ and $l_{2}=1$ state as would be expected from eq (16).

The values of $\alpha_{i}$ for ${ }^{12} \mathrm{C}^{32} \mathrm{~S}_{2}$ are obtained using eq (15); those already available are $\alpha_{1}=1.55 \times 10^{-4} \mathrm{~cm}^{-1}$ [Stoicheff], and $\alpha_{3}=7.11 \times 10^{-4} \mathrm{~cm}^{-1}$ [Guenther et al.]. The experimental figure for $\alpha_{1}+\alpha_{3}, 8.65 \times 10^{-4} \mathrm{~cm}$, derived from $\Delta B$ of $\nu_{1}+\nu_{3}$, is in excellent agreement with that calculated from the published values, 
$8.66 \times 10^{-4} \mathrm{~cm}^{-1}$. For $2 \nu_{1}+\nu_{3}$, the observed figure for $2 \alpha_{1}+\alpha_{3}$ is $1.035 \times 10^{-4} \mathrm{~cm}^{-1}$, compared with the calculated value of $1.021 \times 10^{-4} \mathrm{~cm}^{-1}$; the agreement in this case is adequate. For the $\nu_{1}+2 \nu_{2}^{\circ}+\nu_{3}$ band $\Delta B$ is $4.562 \times 10^{-4} \mathrm{~cm}^{-1}$, so that using the published values of $\alpha_{1}$ and $\alpha_{3}, \alpha_{2}^{\circ}$ comes out at $-2.05 \times 10^{-4}$ $\mathrm{cm}^{-1}$; this is in good agreement with the result derived by Wilkinson from unpublished observations. It would seem therefore that the present figure of $4.562 \times 10^{-4}$ for $\alpha_{1}+2 \alpha_{2}^{\circ}+\alpha_{3}$ can be confidently used to calculate $B_{e}$, which with $B_{0}=0.10910 \mathrm{~cm}^{-1}$, is $0.10932^{8} \mathrm{~cm}^{-1}$. The corresponding value for $r_{e}$ is $1.5529 \mathrm{~A}$.

The results of the calculations for the $\alpha_{i}$ derived from observations on the hot bands are shown in table 2, which includes those previously published. The present measurements for these bands are less precise and the agreement is probably as good as can be expected.

Table 1 also includes the results of the analyses of one very weak band of the isotopic species ${ }^{13} \mathrm{C}^{32} \mathrm{~S}_{2}$. The value of the ground state constant $R_{000}$ is 0.1090 $\mathrm{cm}^{-1}$, which hardly differs from that of ${ }^{12} \mathrm{C}^{32} \mathrm{~S}_{2}$, as would be expected; the corresponding value of $r_{0}$ is $1.554_{6} \mathrm{~A}$. Isotopic substitution has not altered the equilibrium C-S internuclear distance [compare the results of Guenther (see ref [5]), on the species $\left.{ }^{12} \mathrm{C}^{32} \mathrm{~S}^{34} \mathrm{~S}\right]$.

The anharmonicity constants derived from eq (1) were calculated for ${ }^{12} \mathrm{C}^{32} \mathrm{~S}_{2}$ using the ten frequencies shown by (b) in table 3. The five Raman frequencies are the same as those used by Stoicheff (see ref [1]), and so the corresponding anharmonicity constants are identical. The five infrared frequencies were chosen to give the best all round agreement between the observed and calculated figures for the fourteen remaining bands. It is unfortunate that there is no recent determination available for $\nu_{2}^{1}$, which must be used to calculate $\mathrm{g}_{22}$. The values computed for the constants are $\left(\right.$ in $\left.\mathrm{cm}^{-1}\right)$ :

$$
\begin{aligned}
& \omega_{1}^{\circ}=659.23 ; \quad \mathrm{X}_{11}=-1.25 ; \quad \mathrm{X}_{12}=-7.74 ; \\
& \omega_{2}^{\circ}=396.55 ; \quad \mathrm{X}_{22}=+2.25 ; \quad \mathrm{X}_{23}=-6.44 ; \\
& \omega_{3}^{\circ}=1541.82 ; \quad \mathrm{X}_{33}=-6.52 ; \quad \mathrm{X}_{13}=-7.79 ; \mathrm{g}_{22}=-2.00
\end{aligned}
$$

where only the values of $\mathrm{X}_{23}$ and $\mathrm{X}_{33}$ are not affected by Fermi resonance.

Table 3 shows that the differences between the observed and calculated frequencies are not too serious except for the $\nu_{1}+2 \nu_{2}^{\circ}+\nu_{3}$ and $13^{1} 1-01^{1} 0$ bands. The other discrepancies are explicable either because $Q$ branch measurements were used for most of the Raman lines, or more probably because of Fermi resonance between many of the levels.

Fermi resonance occurs between many of the vibrational levels of $\mathrm{CS}_{2}$ and has already been discussed in detail by Stoicheff (1958). He used the frequencies denoted by $\mathrm{c}$ in table 3 to evaluate $\omega_{1}^{\circ}, \omega_{2}^{\circ}, \mathrm{x}_{11}, \mathrm{x}_{22}, \mathrm{x}_{12}, \mathrm{~g}_{22}$, together with $\delta$ (the separation of the unperturbed levels 100 and $\left.02^{\circ} 0\right)$, and $W$, the matrix element, of the cubic term $\alpha_{122}$ in the potential energy, which gives rise to the perturba-

\begin{tabular}{|c|c|c|c|c|}
\hline & $\Pi_{c}^{+}$ & $\Pi_{d}^{-}$ & A verage & \\
\hline $\begin{array}{l}101-000 \\
11^{\prime} 1-01^{\prime} 0\end{array}$ & $\begin{array}{l}\left(\alpha_{1}+\alpha_{3}\right)+=8.58 \\
\alpha_{2}+=-3.8\end{array}$ & $\begin{array}{l}\left(\alpha_{1}+\alpha_{3}\right)-=8.45 \\
\alpha_{2}{ }^{-}=-3.8\end{array}$ & $\begin{array}{l}\left(\alpha_{1}+\alpha_{3}\right)=8.65 \\
\left(\alpha_{1}+\alpha_{3}\right) \pm=8.52 \\
\alpha_{2} \pm=-3.8\end{array}$ & $\begin{array}{l}\text { (a) } \\
\text { (a) }\end{array}$ \\
\hline $\begin{array}{l}201-000 \\
11^{\prime} 1-01^{\prime} 0\end{array}$ & $\begin{array}{l}\left(2 \alpha_{1}+\alpha_{3}\right)+=8.85 \\
\alpha_{2}{ }^{+}=-3.3\end{array}$ & $\begin{array}{l}\left(2 \alpha_{1}+\alpha_{3}\right)-=8.75 \\
\alpha_{2}^{-}=-4.3\end{array}$ & $\begin{array}{l}\left(2 \alpha_{1}+\alpha_{3}\right)=10.35 \\
\left(2 \alpha_{1}+\alpha_{3}\right) \pm=8.80 \\
\alpha_{2} \pm=-3.8\end{array}$ & $\begin{array}{l}\text { (a) } \\
\text { (a) }\end{array}$ \\
\hline $12^{\circ} 1-000$ & & & $\left(\alpha_{1}+2 \alpha_{2}{ }^{\circ}+\alpha_{3}\right)=$ & (a) \\
\hline $13^{\prime} 1-01^{\prime} 0$ & $\begin{array}{c}\left(\alpha_{1}+2 \alpha_{2}+\alpha_{3}\right)+ \\
=+5.2 \\
\alpha_{2}{ }^{+}=-3.6\end{array}$ & $\begin{array}{l}\left(\alpha_{1}+2 \alpha_{2}+\alpha_{3}\right)- \\
=4.4 \\
\alpha_{2}{ }^{-}=-4.6\end{array}$ & $\begin{array}{l}4.562 \\
\left(\alpha_{1}+2 \alpha_{2}+\alpha_{3}\right) \pm \\
=4.8 \\
\left(\alpha_{2} \pm\right)=-4.1\end{array}$ & (a) \\
\hline $\begin{array}{l}003-000 \\
01^{\prime} 3-01^{\prime} 0\end{array}$ & $\begin{array}{l}\alpha_{3}+=7.087 \\
\alpha_{2}+=-2.22\end{array}$ & $\begin{array}{l}\alpha_{3}{ }^{-}=7.096 \\
\alpha_{2}{ }^{-}=-2.89\end{array}$ & $\begin{array}{l}\alpha_{3}=7.11 \\
\alpha_{3} \pm=7.09 \\
\alpha_{2} \pm=-2.56\end{array}$ & $\begin{array}{l}\text { (b) } \\
\text { (b) }\end{array}$ \\
\hline
\end{tabular}

TABLE 2. The constants $\alpha_{i}$ derived from the hot bands [in units of $10^{-4} \mathrm{~cm}^{-1}$ ]

a Present work.

b A. H. Guenther, T. A. Wiggins \& D. H. Rank, J. Chem. Phys. 28, 682-7 (1958).

\begin{tabular}{|c|c|c|c|}
\hline Assignment & $\nu$ obs., $\mathrm{cm}^{-1}$ & $\nu$ calc., $\mathrm{cm}^{-1}$ & $\Delta \nu$ obs. calc., $\mathrm{cm}^{-1}$ \\
\hline $\begin{array}{c}13^{10}-03^{10} \\
1220-0220 \\
1200-0200 \\
2110-0110 \\
110-010 \\
200-100 \\
100-000 \\
0200-000 \\
03^{10} 0-011^{10} \\
0400-0200 \\
04^{2} 0-0220\end{array}$ & $\begin{array}{r}637.76 \\
\text { c } 643.64 \\
\text { ○ } 645.02 \\
648.01 \\
\text { c } 650.24 \\
\text { c } 655.49 \\
\text { × } 657.98 \\
\text { c } 802.11 \\
\text { c } 811.12 \\
\text { c } 818.15 \\
\text { c } 819.18\end{array}$ & $\begin{array}{l}634.76 \\
642.50 \\
642.50 \\
647.75 \\
\text { (b) } \\
\text { (b) } \\
\text { (b) } \\
\text { (b) } \\
\text { (b) } \\
820.13 \\
820.13\end{array}$ & $\begin{array}{l}+3.0 \\
+1.14 \\
+2.52 \\
+0.26\end{array}$ \\
\hline
\end{tabular}

TABLE 3A. Observed and calculated frequencies of ${ }^{12} \mathrm{C}^{32} \mathrm{~S}_{2}$

I. Raman lines

All Raman data, B. P. Stoicheff, Can. J. Phys. 36, 218-30 (1958). This part of the table is the same as that given by him.

${ }^{a}$ Band origin; all other observed frequencies are measurements of sharp $Q$ branches.

Frequencies used to calculate the anharmonic constants.
c Frequencies used to calculate the anharmonic constants corrected for Fermi

\begin{tabular}{|c|c|c|c|c|}
\hline \multicolumn{5}{|c|}{ Infrared bands } \\
\hline Assignment & $\nu$ obs., $\mathrm{cm}^{-1}$ & $\nu$ ealc., $\mathrm{cm}^{-1}$ & $\triangle \nu$ obs-calc., $\mathrm{cm}^{-1}$ & $(\mathrm{x})$ \\
\hline $\begin{array}{l}396.8(\mathrm{Q})^{* *} \\
877.37 \\
1535.35^{* *} \\
2171.42 \\
2185.92^{* *} \\
2324.54^{* *} \\
2811.350 \\
2833.191 \\
2959.117 \\
2961.791 \\
4528.09 \text { (est) } \\
4547.464^{* *} \\
4566.860^{* *}\end{array}$ & $\begin{array}{l}01^{10-000} \\
001-100 \\
001-000 \\
1111-01^{110} \\
101-000 \\
02^{0} 1-000 \\
21^{11}-01^{110} \\
201-000 \\
131-01^{10} \\
12^{\circ} 1-000 \\
0223-0220 \\
01^{13}-0110 \\
003-000\end{array}$ & $\begin{array}{c}(*) \\
877.32 \\
1535.30 \\
2171.31 \\
\left(^{*}\right) \\
2324.53 \\
2811.268 \\
\left(^{*}\right) \\
2954.063 \\
2959.236 \\
4528.15 \\
\left(^{*}\right) \\
\left(^{*}\right)\end{array}$ & $\begin{array}{c}+0.05 \\
+0.05 \\
+0.11 \\
+0.01 \\
0.082 \\
+5.054 \\
+2.555 \\
+0.06\end{array}$ & $\begin{array}{l}\text { (a) } \\
\text { (b) } \\
\text { (b) } \\
\text { (c) } \\
\text { (c) } \\
\text { (b) } \\
\text { (c) } \\
\text { (c) } \\
\text { (c) } \\
\text { (c) } \\
\text { (d) } \\
\text { (d) } \\
\text { (d) }\end{array}$ \\
\hline
\end{tabular}
resonance.

TABLE 3B. Observed and calculated frequencies of ${ }^{12} \mathrm{C}^{32} \mathrm{~S}_{2}$

a G. Herzberg, Infra-red and Raman Spectra, p. 277 (1945).

b G. R. Wilkinson, unpublished results.

c Present work.

d A. H. Guenther, T. A. Wiggins and D. H. Rank, J. Chem. Phys. 28, 682-7 (1958).

Except in the cases indicated, the frequencies quoted are band origins. For * and ${ }^{* *}$, see $\mathrm{b}$ and $\mathrm{c}$, respectively, in table $3 \mathrm{~A}$.

tion between the 100 , and $02^{\circ} 0$ levels. The sign of $W$ was found from the experimental value of the rotational constant $\alpha_{2}$. Using the same data and methods it seems that slight modifications are needed for some of the constants (table 4). 
TABLE 4. Frequencies for infinitesimal amplitudes and vibrational constants of ${ }^{12} \mathrm{C}^{32} \mathrm{~S}_{2}\left[\right.$ in $\left.\mathrm{cm}^{-1}\right]$

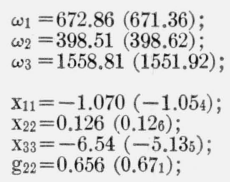

$\omega_{1}^{0}=668.72(668.69)$; $\omega_{2}^{0}=395.97(395.97)$; $\omega_{3}{ }^{0}=1541.89(1537.64)$

$\mathrm{x}_{12}=0.860\left(0.86_{1}\right)$;

$\mathrm{x}_{13}=-7.86(-4.95)$

$\mathrm{X}_{23}=-6.45(-6.67)$

$W=-36.05(-36.05)$

$\delta=124.80(124.80)$

Figures in parentheses are those calculated by Stoicheff

The frequencies $3 \nu_{3}, 3 \nu_{3}+\nu_{2}^{1}-\nu_{2}^{1}$ and $\nu_{3}$ are used to obtain $\omega_{3}^{\circ}, \mathrm{x}_{33}$ and $\mathrm{x}_{23},{ }^{4}$ all these are uncomplicated by Fermi resonance. Since new and improved infrared data are now available, the present values are more reliable than those listed by Stoicheff. To calculate $\mathrm{x}_{13}$ Stoicheff was forced to assume that the diad $\left(\nu_{1}+\nu_{3}\right),\left(2 \nu_{2}^{\circ}+\nu_{3}\right)$ could be described by the same values of $\delta$ and $W$ as $\nu_{1}$ and $2 \nu_{2}^{\circ}$. The frequency of $\left(2 \nu_{2}^{\circ}+\nu_{3}\right)$ is now available, and it appears that this assumption is not correct. The value of $\mathrm{x}_{13}$ can be calculated directly from the sum of the two frequencies $\left(\nu_{1}+\nu_{3}\right)+\left(2 \nu_{2}^{\circ}+\nu_{3}\right)=4510.032$ $\mathrm{cm}^{-1}$ and is seen to differ significantly from that proposed earlier. Table 4 also includes revised values for the frequencies at infinitesimal amplitudes.

The twelve constants in table 4 are derived from nine Raman and six infrared frequencies; of the remaining nine frequencies, only one $02^{2} 3-02^{2} 0$ (obs. (est). $4528.09 \mathrm{~cm}^{-1}$, calc., $4528.12 \mathrm{~cm}^{-1}$ ) is not affected by Fermi resonance. The other eight frequencies are all members of incomplete Fermi polyads, so that it is unfortunately not possible to

${ }^{4}$ In table $3 \nu_{1}+\nu_{3}$ was used instead of $\nu_{3}$ to get these constants as at that time no figure was available for the latter frequency; the two sets of values are nearly identical. get any checks on the constants corrected for Fermi interaction.

The Fermi resonance between the levels $\nu_{1}$ and $2 \nu_{2}^{\circ}$ (and corresponding levels) in $\mathrm{CS}_{2}$ is quite weak $\left(\delta=124.80 \mathrm{~cm}^{-1}\right)$ and is not as important as in the analogous molecule $\mathrm{CO}_{2}$ (compare Courtoy [14]). Even so, the shift of the observed levels $( \pm 9.67$ $\mathrm{cm}^{-1}$ for $2 \nu_{2}^{\circ}$ and $\nu_{1}$ ) is quite large, and the calculated values of the anharmonic constants, taking the interaction into account, differ, in most cases, markedly from the uncorrected values. New observations on other frequencies and more accurate data on $\nu_{2}^{1}$ would be most desirable to provide checks on the values of the constants listed in table 4 .

\section{References}

[1] B. P. Stoicheff, Can. J. Phys. 36, 218 (1958).

[2] H. W. Schrötter, Z. Elektrochem. 64, 853 (1960).

[3] H. C. Allen, E. K. Plyler, and L. R. Blaine, J. Am. Chem. Soc. 78, 4843 (1956)

[4] A. H. Guenther, T. A. Wiggins, and D. H. Rank, J Chem. Phys 28, 682 (1958).

[5] A. H. Guenther, J. Chem. Phys. 31, 1095 (1959).

[6] G. R. Wilkinson, Dept. of Physies, King's College, London, unpublished results.

[7] Earle K. Plyler and L. R. Blaine, J. Research NBS 62, 7 (1959).

[8] Earle K. Plyler, L. R. Blaine, and E. D. Tidwell, J. Research NBS 55, 279 (1955).

[9] G. Herzberg, Infra-red and Raman spectra (D. Van Nostrand, New York, 1945).

[10] H. H. Nielsen, Rev. Mod. Phys. 23, 90 (1951).

[11] G. Herzberg, Rev. Mod. Phys. 14, 219 (1942).

[12] H. H. Nielsen, G. Amat, and M. Goldsmith, J. Chem Phys. 26, 1060 (1957)

[13] E. D. Tidwell, E. K. Plyler, and W. S. Benedict, J. Opt. Soc. Am. 50, 1243 (1960).

14] C. P. Courtoy, Can. J. Phys. 35, 608 (1957).

(Paper 66A3-161) 


\section{Publications of the National Bureau of Standards*}

\section{Selected Abstracts}

\author{
The systems of electrical units, F. B. Silsbee, NBS J. Research \\ 66C (Eng. and Instr.) No. 2 (Apr.-June 1962) 75 cents.
}

The various systems of measurement, with their respective sets of units, used in the literature on electricity and magnetism are described in detail. Their historical development is summarized. The manner in which each is derived from either of the two alternative points of view of the experimentalist and the theoretician is compared and contrasted. The desirability of recognizing both points of view in international standardization, particularly when discussing rationalization, is pointed out. The present status of the absolute measurements on which all electrical units are based is reported, and tables are included for the conversion of equations and numerical values from one system to another.

Currents induced on the surface of a conducting circular cylinder by a slot, G. Hasserjian and A. Ishimaru, J. Research NBS 66D (Radio Prop.) No. 3 (May-June 1962) 7o cents.

This paper is a partial study of currents induced on circular, conducting cylinders by narrow radiating slots. First, a brief and general formulation of the radiation fields of slots on cylinders is made. Then, the problem of an infinite axial slot is examined thoroughly for all cylinder sizes. An expansion for the fields, very close to the slot, on large radius cylinders, is also obtained. Sample computations are made, for various ranges of cylinder radius, and the order of the errors is discussed.

The problem of a circumferential slot, of constant excitation, is also considered. An asymptotic expansion obtained for this case yields the surface current distribution for values o axial distances that are smaller than the square of the circumference of the cylinder.

Since one of the objectives of this study is to determine mutual coupling between two slots on a cylinder, the last section presents a formulation of the equivalent network in terms of the surface and feed line currents.

Preparation, transfer, and dilution of a $50 \%$ sodium hydroxide solution, R. G. Bates, Chem.-Anal. 50, No. 4, 117 118 (Dec. 1961).

An arrangement for the handling of 50-percent sodium hydroxide solution without contamination by carbon dioxide and silica is described. The apparatus utilized polyethylene vessels and a sintered filter crucible of stainless steel.

Relative intensities for the arc spectra of seventy elements, W. F. Meggers, C. H. Corliss, and B. F. Scribner, Spectrochim. Acta 17, No. 11, 1137-1172 (Nov. 1961).

The relative intensities, or radiant powers, of 39,000 spectral lines with wavelengths between 2000 and $9000 \mathrm{~A}$ have been determined on a uniform energy scale for seventy chemical elements. This was done by mixing 0-1 at. percent of each element in powdered copper, pressing the powder mixture to form solid electrodes which were burned in a $10-\mathrm{A}, 220-\mathrm{V}$ d.c. arc, and photographing the spectra with a stigmatic concave grating while a step-sector was rotating in front of the slit. The sectored spectrograms facilitated the estimation of intensities of all element lines relative to copper lines which were then calibrated on an energy scale provided by standardized lamps, and all estimated line intensities were finally adjusted to fit this calibration. Comparisons with other intensity measurements in individual spectra indicate that the spectral-line intensities may have errors of 20 percent, but they first of all provide uniform quantitative values for the seventy chemical elements commonly determined by spectrochemists.
The complete data are being published as a National Bureau of Standards Monograph. About 1100 of the lines are presented in this paper as a list of the strong lines of each element. Energy levels and term combinations are given for each classified line.

Calibration of vibration pickups at large amplitudes, E. Jones, S. Edelman, and K. S. Sizemore, J. Acoust. Soc. Am. 33, No. 11, 1462-1466 (Nov. 1961).

Axial resonances of long rods and tubes were used to generate motion for accurate calibration of vibration pickups over the frequency range from below 1 to above $20 \mathrm{kc}$ at acceleration levels up to $12,000 \mathrm{~g}$. The resonators were driven by an electromagnetic shaker at low frequencies and by a piezoelectric ceramic stack shaker at high frequencies. Vibration amplitude was measured optically by means of a microscope using stroboscopic light and by means of the interference fringe disappearance technique. Adequate overlap between the two methods was achieved by going up to the 60th disappearance of the fringes. A simple, direct measurement of the phase angle between the pickup signal and the motion is described. Construction details of a small, light pickup which is unaffected by the high acceleration levels are given.

Infrared spectrum of acetylene, T. A. Wiggins, E. K. Plyler, and E. D. Tidwell, Opt. Soc. Am. 51, No. 11, 1219-1225 (Nov. 1961).

The infrared absorption spectrum of $\mathrm{C}_{2} \mathrm{H}_{2}$ has been studied in the region from 2500 to $4150 \mathrm{~cm}^{-1}$. Nineteen bands were observed of which eleven were sufficiently intense and well resolved to permit rotational analysis. Five bands involving the ground vibrational state were analyzed giving the rotational constants $\mathrm{B}_{0}=1.17654 \pm 0.00004$ and $\mathrm{D}_{0}=1.51 \pm 0.03$ $\times 10^{-6} \mathrm{~cm}^{-1}$.

The l-doubling constants for the degenerate modes were determined to be $\mathrm{q}_{4}=5.2_{7}, \mathrm{q}_{5}=4.6_{3} \times 10^{-3} \mathrm{~cm}^{-1}$. The rotational constants determined for the various observed states clearly show that additional data will be needed and due account taken of resonances to obtain a satisfactory set of rotational constants.

The use of difference bands involving the $\mathrm{v}_{4}=1$ level permits the determination of the vibrational frequency of that level to be $612.88 \mathrm{~cm}^{-1}$.

A status report on Algol-60, J. H. Wegstein, Datamation, $p$. 24 (1961)

The present status of the ALGOL-60 computer language is indicated by referring to the numerous publications on the language, the compilers, and the algorithms. Maintenance organizations are described and an indication of the compilerwriting effort is given.

A method for the study of vector velocity distribution of low density molecular beams, L. Marton, S. R. Mielczarek, and D. C. Shubert, Book, Rarefied Gas Dynamics, pp. 61-65 (Academic Press, Inc., New York, N.Y., 1961).

It is possible to detect the presence of a rarefied gas beam by means of the electron optical schilaren method. Certain modifications of this method are described by means of which the instrument yields data of the vector velocity distribution of a molecular beam before and after interaction with a surface. With this information, one can compute the thermal accommodation and viscous slip coefficients in the interaction. The principle of the modified electron optical schilaren method is explained, and a schematic diagram of the apparatus is shown.

Rate of vaporization of refractory substances, J. J. Diamond, J. Efimenko, R. F. Hampson, and R. F. Walker, J. H. de Boer, et al. (Editors) Reactivity of Solids Proc. Fourth Intern. Symp., Amsterdam, 1960, 725-34 (1960).

The more important factors affecting the rate of vaporization of solid systems are summarized. Techniques for measuring 
the rates of vaporization of refractory substances at temperatures in the $1600-3000^{\circ} \mathrm{C}$ range are briefly described. The techniques pertain to measurements both in vacuum and in the presence of foreign gases. Some of the factors and the experimental techniques are illustrated by brief reference to studies of the vaporization of platinum and aluminum oxide.

The effect of lithium bromide on the structural transition of ribonuclease in solution, L. Mandelkern and D. E. Roberts J. Am. Chem. Soc. 83, 4292 (1961).

The specific rotation as a function of temperature for dilute aqueous $\mathrm{LiBr}$ solutions of ribonuclease was measured. Though the low rotation decreased with increasing $\mathrm{LiBr}$ concentration the ordered structures present in the native protein became thermodynamically less stable. Consequently the apparent discrepancy that existed between the previous interpretation given to the optical rotatory data and the behavior of the fibrous proteins immersed in aqueous $\mathrm{LiBr}$ solutions is removed.

Lower bounds for eigenvalues of Schrodinger's equation, $\mathrm{N}$. W. Bazley and D. W. Fox, Phys. Rev. 124, No. 2, 483-492 (Oct. 1961).

This paper gives new results that are useful in estimation of eigenvalues of Schrodinger's equation. Numerical applications are made for the helium atom, an anharmonic oscillator, and a radial Schrodinger equation.

Polymorphism of $\mathrm{ABO}_{3}$ type rare earth borates, E. M. Levin, Roth, and J. B. Martin, Am. Mineralogist 46, 1030-1055 R. S. (Sept. 1961).

Polymorphic relationships as a function of temperature and ionic radius were investigated for thirteen $\mathrm{ABO}_{3}$-type borates, including all of the normally trivalent rare earth ions as well as $\mathrm{La}^{+3}, \mathrm{Y}^{+3}$, $\mathrm{In}^{+3}$, and $\mathrm{Mn}^{+3}$. The melting points of the compounds varied irregularly from $1660^{\circ} \mathrm{C}$ for $\mathrm{LaBO}_{3}$ to $1540^{\circ} \mathrm{C}$ for $\mathrm{EuBO}_{3}$. In general, the borate compounds exhibited the same structure types as the three forms of $\mathrm{CaCO}_{3}$, i.e., aragonite, vaterite, and calcite. Compounds of the larger ions, $\mathrm{LaBO}_{3}$ and $\mathrm{NdBO}_{3}$, showed the aragonite-type structure at low temperature. These compounds were found to have a reversible transformation at $1488^{\circ} \mathrm{C}$ and $1090^{\circ} \mathrm{C}$, respectively. The high-temperature forms were different from each other, and both exhibited low symmetry. The following borates showed a stable vaterite-type phase: $\mathrm{SmBO}_{3}, \mathrm{EuBO}_{3}$ $\mathrm{GdBO}_{3}, \mathrm{DyBO}_{3}, \mathrm{YBO}_{3}, \mathrm{HoBO}_{3}, \mathrm{ErBO} \mathrm{C}_{3}, \mathrm{TmBO}_{3}, \mathrm{YbBO}_{3}$, and $\mathrm{LuBO}{ }_{3}$. Above $1285^{\circ} \mathrm{C}, \mathrm{SmBO}_{3}$ inverted to the high-NdBO type polymorph. Below $1310^{\circ} \mathrm{C}, \mathrm{LuBO}_{3}$ formed the calcitetype structure. No polymorphism was observed in the eight intermediate borates. Indium borate showed only the calcitetype structure. A discussion of the factors affecting polymorphism, such as radius ratio, density, and pressure, in addition to interpretation of infra-red and structure data may explain why the vaterite-type structure is more stable in the borates than in the carbonates. Unit cell dimensions are listed for indexed X-ray diffraction powder patterns, together with limited optical data. Published X-ray powder data for vaterite are compared.

Dielectric properties of solid polymers, A. J. Curtis, SPE Trans., 82-85 (Jan. 1962).

The general dielectric properties of solid polymers are discussed in terms of molecular structure and degree of amorphicity. In general, both in amorphous and in semicrystalline polar polymers, a dielectric relaxation process is observed which is related to the onset of molecular motions in the region of the so-called glass transformation. In many amorphous materials at least one other relaxation process has been observed at lower temperatures. In many cases, e.g., the polyacrylates, the low temperature relaxation process has been attributed to rotation of polar side groups. However, in some cases, such as poly(vinyl chloride), no polar side groups are known to exist. The relaxation spectrum of semicrystalline materials is generally more complex: some materials are known to exhibit as many as four separate relaxation processes. Measurements of several polymers demonstrating these phenomena are described. Possible interpretations in terms of multiple phases and discrete modes of motion are described which are consistent with the di- electric results as well as dynamic mechanical and NMR measurements.

Chemicals reactions at very low temperatures, A. Thomas, Trans. Faraday Soc. 57, 1679-1685 (Oct. 1961).

It is not normally possible to conduct free radical reactions so that only a single elementary step in the reaction sequence takes place, because the products of reaction are extremely reactive. In an attempt to control these reactions more closely and to preserve the very reactive radical chain carriers as products of primary reaction, a novel reactor has been designed and constructed for use of the temperature of liquid helium. The two participants in a reaction are laid down as alternate solid layers on top of each other; the more reactive species being deposited as a fraction of a mono-layer sandwiched between several monolayers of the less reactive material. The reactants are condensed on the outside surface of a spinning refrigerated drum to produce multilayer deposits about 0.1 to $0.5 \mathrm{~mm}$ thick.

Preliminary results suggest that $\mathrm{HCO}$ was preserved when hydrogen atoms were deposited between layers of solid carbon monoxide, but no evidence of the existence of $\mathrm{HO}_{2}$ was found when hydrogen atoms were interspersed between layers of oxygen molecules.

Departure from the Saha equation for ionized helium II. Atmospheric thicknesses too small to satisfy detailed balance in the resonance lines, R. N. Thomas and J. B. Zirker, Astrophys. J. 134, 740-746 (Nov. 1961).

The results of the preceding paper for the variation of the source-function in a finite atmosphere are applied to the case of He II. A two-level atom is shown to be adequate for the treatment of the ionization equilibrium. Some comment is made on the observed values of $\operatorname{Ly} \alpha, \operatorname{Ly} \beta$, and $\lambda 4686$.

Electron diffraction studies on solid $\alpha$-nitrogen, E. M. Horl and L. Marton, Acta Cryst. 14, No. 11, Pt. 1 (Jan. 1961).

A technique was developed for studying thin films of solidified permanent gases by means of electron transmission diffraction. It was applied to the investigation of thin films of solid $\alpha$ nitrogen at 4 and $20{ }^{\circ} \mathrm{K}$. The orientation of the microcrystallites on aluminum and Formvar substrates was investigated as a function of both the temperature of the substrate and the intensity of the molecular nitrogen beam during deposition. Further, the crvstal structure and the cell dimensions of $\alpha$-nitrogen were reinvestigated. Faults in the stacking sequence of (111) planes, detected under certain conditions, were studied in some detail. Preferential crystal growth processes were observed to be induced by electron bombardment. The influence of conditions of deposition on these processes was also investigated.

Franck-Condon factors and the shape of ionization efficiency curves, M. E. Wacks and M. Krauss, J. Chem. Phys. 35, No. 5, 1902-1903 (Nov. 1961).

Franck-Condon factors for the transitions

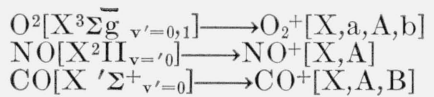

were computed on the 704 at NBS. With these factors the ionization efficiency curves were synthesized for $\mathrm{O}_{2}$ and $\mathrm{NO}$ and compared with previously published experimental curves of other authors.

Memory effects in irreversible thermodynamics, R. Zwanzig, Phys, Rev. 124, No. 4, 983-992 (Nov. 15, 1961).

A new generalization of Onsager's theory of irreversible processes is presented. The main purpose is to allow for memory effects or causal time behavior, so that the response to a thermodynamic force comes later than the application of the force. This is accomplished by a statical mechanical derivation of an exact non-Markoffian kinetic equation for the probability distrubution in the space of macroscopic state variables. The memory effect in the resulting transport equations is represented by a time convolution of the thermodynamic forces with memory functions. The latter are timecorrelation functions in the rates of change of the phase functions corresponding to macroscopic quantities. The resulting 
transport equations are not restricted to small deviations from thermal equilibrium. Onsager's theory is shown to be the low frequency limit of our causal theory.

Drift mobility of an ionic impurity in an electric field, J. R. Manning, Phys. Rev. 125, No. 1, 103-108 (Jan. 1962).

The effect of an electric field on the diffusion of an ionic impurity is studied from an atomistic viewpoint. When diffusion occurs by either a vacancy or interstitialcy mechanism, there will be two effects of the field on the diffusion process. First, the field will exert a direct force on the electrically charged ions. This will effectively change the energy of motion for an ion jump in the direction of the field. Secondly, the field will give rise to a net flow of vacancies or interstitialcies. This will cause the vacancies or interstitialcies to approach an ion more frequently from one direction and less frequently from the opposite direction. As a result, the frequency of diffusive jumps in one direction will be increased and that in the opposite direction will be decreased. It is shown that the drift mobility $\mu$ of an ionic impurity in an electric field can be found from consideration of these two effects, with $\mu$ being related to $\mathrm{D}^{*}$, the tracer diffusion coefficient of the impurity in the absence of an electric field. Explicit expressions are derived giving the value of $\mu / D^{*}$ for various cubic lattices. Both vacancy and interstitialcy mechanisms are treated.

Some observations of metal distribution, F. Ogburn and M. A. Morris, Plating Mag. 49, No. 1, 72-75 (Jan 1962). Experimental data are given which demonstrate the effect of current density on metal distribution on a macro scale. Decreasing the current density leads to more uniform metal distribution of copper deposited from an acid copper solution and of nickel from a Watts nickel solution. For an acid copper bath with $0.01 \mathrm{~g}$ /liter of animal glue, a low current density yields deposits which may be thinner on corners than on adjacent flat surfaces.

\section{Other NBS Publications}

Journal of Research 66C (Eng. and Instr.) No. 2 (Apr.-June 1962) 75 cents.

Effect of vibration and shock on unsaturated standard cells. R. J. Brodd and W. G. Eicke, Jr.

Experiments on the burning of cross piles of wood. D. Gross.

Transfer of NBS X-ray beam calibrations. J. S. Pruitt, A. Allisy, G. Joyet, W. Pohlit, M. Tubiana, and C. Zupaněiě.

Identification of metallurgical reactions and their effect on the mechanical properties of $17-7 \mathrm{PH}$ stainless steel H. C. Burnett, R. H. Duff, and H. C. Vacher.

The ideal Lovibond color system. D. B. Judd, G. J. Chamberlin, and G. W. Haupt.

Systems of electrical units. F. B. Silsbee. (See above abstract.)

Journal of Research 66D (Radio Prop.) No. 3 (May-June 1962) 70 cents.

A theory of radar reflections from a rough moon. D. F Winter.

A lunar theory reasserted. K. M. Siegel and T. B. A. Senior.

Statistical distribution of the amplitude and phase of a multiply scattered field. P. Beckmann.

Amplitude distribution for radio signals reflected by meteor trails, II. A. D. Wheelon.

High resolution pulse measurements of meteor-burst propagation at $41 \mathrm{Mc} / \mathrm{s}$ over a 1,295-km path. R. J. Carpenter and Gerard R. Ochs.

Ionospheric irregularities and long-distance radio propagation. H. A. Whale.

On the role of the process of reflection in radio wave propagation. F. du Castel, P. Misme, A. Spizzichino, and J. Voge.

Correlation between hourly median scattered signals and simple refractivity parameters. A. S. Dennis.

Observations of radio wave phase characteristics on a highfrequency auroral path. J. W. Koch and W. M. Beery.

Diurnal and seasonal changes in structure of the mid-latitude quiet ionosphere. J. W. Wright.
Schumann resonances of the earth-ionosphere cavity-extremely low frequency reception at Kingston, R. I. C. Polk and F. Fitchen.

Propagation of plane electromagnetic waves past a shoreline. J. Bazer and S. N. Karp.

Currents induced on the surface of a conducting circular cylinder by a slot. G. Hasserjian and A. Ishimaru. (See above abstract)

Research highlights of the National Bureau of Standards, Annual Report, fiscal year 1961. NBS Misc. Publ. 242 (Dec. 1961) 75 cents.

Report of the 46th National Conference on Weights and Measures, 1961. NBS Misc. Publ. 239 (Jan. 1962) 65 cents.

Quarterly radio noise data, June, July, August 1961, W. Q. Crichlow, R. T. Disney, and M. A. Jenkins, NBS Tech. Note 18-11 (PB151377-11) (1961) \$1.50.

A note on the propagation of certain LF pulses utilized in a radio navigation system, J. R. Johler, NBS Tech. Note 118 (PB161619) (1961) 75 cents.

Computer simulation of street traffic, M. C. Stark, NBS Tech. Note 119 (PB161620) (1961) \$2.25.

Precision calibration of $\mathrm{RF}$ vacuum tube voltmeters, L. F. Behrent, NBS Tech. Note 121 (PB161622) (1961) 50 cents. Papers from the symposium on collision phenomena in astrophysics, geophysics, and masers, M. J. Seaton, M. J. Dalgarno, and C. Pecker, NBS Tech. Note 124 (PB161625) (1961) $\$ 1.00$.

A waveguide interpretation of "temperatel-atitude spread F" on equatorial ionograms, M. L. V. Pitteway and R. Cohen, J. Geophys. Research 66, 3141-3156 (Oct. 1961).

Ground-conductivity determinations at low radio-frequencies by an analysis of the sferic signatures of thunderstorms, J. R. Johler and C. M. Lilley, J. Geophys. Research 66, 3233-3244 (Oct. 1961).

Tongs used in testing for radioactive contamination, T. G. Hobbs, Health Physics 6, No. 3 \& 4, 224a, 224b, 225 (Oct. 1961)

For a unified grain-size standard, L. L. Wyman and P. E. Penrod, Materials Research \& Standards (ASTM Bull.) 1, No. 8, 638 (Aug. 1961)

Sound absorption by areas of finite sizes, R. K. Cook, Proc. 3d Intern. Congress on Acoustics (Elsevier Publishing Co., Amsterdam, 1961).

Photographic response to successive exposures of different types of radiation, M. Ehrlich and W. L. McLaughlin, J. Opt. Soc. Am. 51, No. 11, 1172-1181 (Nov. 1961).

Wind resistance of asphalt shingle roofing, W. C. Cullen, Natl. Acad. Sci.-Natl. Research Council, 33-42 (1961).

The interpretation and synthesis of certain spread-F configuration appearing on equatorial ionograms, W. Calvert and R. Cohen, J. Geophys. Research 66, 3125-3140 (Oct. 1961)

Kinetic isotope effects in the reaction of methyl radicals with ethane, $-\mathrm{d}_{6}$ and ethane-1, 1, 1- $\mathrm{d}_{3}$, J. R. McNesby, J. Phys. Chem. 64, No. 11, 1671 (Nov. 1960).

Hearing by bone conduction, E. L. R. Corliss, E. L. Smith, and J. O. Magruder, Proc. 3d Intern. Congress on Acoustics, p. 53-55 (Elsevier Publ. Co., Amsterdam, The Netherlands, $1959)$.

Expected influence of a localized change of ionosphere height of VLF propagation, J. R. Wait, J. Geophys. Research 66, 3603 (Oct. 1961).

Cryogenics and nuclear physics, R. P. Hudson, Science 134, No. 3492, 1733-1736 (Dec. 1, 1961).

A technique for calculating infrared absorption by a regular band, L. R. Megill and P. M. Jamnick, J. Opt. Soc. Am. 51, 1294-1297 (Nov. 1961).

Evaluation of the special world interval program during the IGY, M. E. Nason, J. Geophys. Research 66, 3597-3598 (Oct. 1961)

Crack propagation and the fracture of concrete, M. F. Kaplan, J. Am. Concrete Inst. 58, No. 5, 591-610 (Nov. 1961).

Magnetic field micropulsations and electron bremsstrahlung, W. H. Campbell, J. Geophys. Research 66, 3599-3600 (Oct. 1961). 
Timing potentials of Loran C, R. H. Doherty, G. Hefley, and R. F. Linfield, Proc. IRE 49, 1659-1673 (Nov. 1961).

Pan American standards of mutual benefit to Latin America and the U.S., A. T. McPherson, Foreign Commerce Weekly (International Affairs, Department of Commerce, Washington, D.C.) p. 1 (Nov. 13, 1961).

Comments on "Plan for the Self-Qualification of Laboratories", A. T. McPherson, ASTM Materials Research \& Standards 1, No. 9, 729-730, 733 (Sept. 1961).

Technique for calculating infrared absorptance by a regular band, L. R. Megill and P. M. Jamnick, J. Opt. Soc. Am. 51, No. 11, 1294-1297 (Nov. 1961).

Sun storms and the earth: the aurora polaris and the space around the earth, S. Chapman, Am. Scientist 49, No. 3, 249-284 (Sept. 1961).

Maxwell and modern colorimetry, D. B. Judd, J. Photographic Sci. 9, No. 6, 341-352 (Nov.-Dec. 1961).

Colorimetric determination of 5,6-dichloro-2-benzoxazolinone in leathers, S. Dahl, J. Am. Leather Chemists Assoc. LVII, No. 1 (Jan. 1962).

Formation of polymer crystals with folded chains from dilute solution, J. I. Lauritzen, Jr., and J. D. Hoffman, J. Chem. Phys. 31, No. 6, 1680-1681 (Dec. 1959).

This works for us-approval books for a science library, V. S. Barker, Special Libraries 52, No. 3, 471-472 (Oct. 1961).

Theoretical dielectric behavior of an ethyl sterate-heneicosane mixture, M. G. Boradhurst, J. Chem. Phys. 33, No. 1, 221-226 (July 1960).

A statistical comparison of the wearing characteristics of two types of dollar notes, E. B. Randall, Jr., and J. Mandel, Materials Research and Standards (ASTM Bull.) 2, No. 1, 17-25 (Jan. 1962).

Non-additivity in two-way analysis of variance, J. Mandel, J. Am. Stat. Assoc. 56, 878-888 (Dec. 1961).

5,6-dichloro-2-benzoxazolinone as a leather fungicide, S. Dahl and A. M. Kaplan, J. Am. Leather Chemists Assoc. LVI, No. 12, (Dec. 1961).

On the impedance of long wire suspended over the ground, J. R. Wait, Proc. IRE 49, No. 10 (Oct. 1961).

Automatic screening of normal and abnormal electrocardiograms by means of a digital electronic computer, H. V. Pipberger, R. J. Arms, and F. W. Stallmann, Prof. Soc. Experimental Biology and Medicine 106, 130-132 (1961).

Electromagnetic bearing, H. Sixsmith. Rev. Sci. Instr. 32, 1196-1197 (Nov. 1961).

Advances in orthonormalizing computation, P. J. Davis and P. Rabinowitz, Advances in Computers II, 55-133 (1961).

On the average atmospheric radio refractive index structure over North America, B. R. Bean and J. D. Horn, Beitr. Phys. Atmos. 34, 92-104 (1961).

Concerning the bi-exponential nature of the tropospheric radio refractive index, B. R. Bean, Beitr. Phys. Atmos. 34, 81-91 (1961).

Atomic beam frequency standards, R. C. Mockler, Advances in Electronics and Electron Phys. 15, 1-71 (1961).

Traveling pressure waves associated with geomagnetic activity, P. Chrzanowski, G. Greene, K. T. Lemmon, and J. M. Young, J. Geophys. Research 56, No. 11, 3727-3733 (Nov. 1961).

A study of the fluorescence of cellulosic polymers, K. F. Plitt and S. D. Toner, J. Appl. Polymer Sci. 5, No. 534-538 (1961).

Use of an operational amplifier with Helmholtz coils for reducing ac induced magnetic fields, L. A. Marzetta, Rev. Sci. Instr. 32, No. 11, 1192-1195 (Nov. 1961).

Formulae for an accurate intermediary orbit of an artificial satellite, J. P. Vinti, Astronomical J. 66, No. 9, 514-516 (Nov. 1961).

Comments on K. Vozoff's paper "Calibration of pulsation detector coils," J. R. Wait, J. Geophys. Research 66, No. 10, 3603 (Oct. 1961).

Dielectric properties of polyamides, A. J. Curtis, J. Chem. Phys. 34, No. 5, 1849-1850 (May 1961).

Precision of reverberation chamber measurements of sound absorption coefficients, R. V. Waterhouse, Book, Proc. 3 d Intern. Congress on Acoustics, Stuttgart, Germany, p. 886 (Elsevier Publ. Co., Amsterdam, The Netherlands, 1959).

A comment on Ryser's "normal and integral implies incidence" theorm, K. Goldberg, Am. Math. Monthly 68, No. 8, 770-771 (Oct. 1961).

Concerning radiosondes, lag constants, and radio refractive index profiles, B. R. Beam and E. J. Dutton, J. Geophys. Research 66, 3717-3722 (Nov. 1961).

On the interpretation of prominence spectra IV. The Balmer and Paschen continua in a quiet prominence, J. T. Jefferies and F. Q. Orrall, Astrophys. J. 134, No. 3, 747 (Nov. 1961).

*Publications for which a price is indicated (except for Technical Notes) are available only from the Superintendent of Documents, U.S. Government Printing Office, Washington 25, D.C. (foreign postage, one-fourth additional). Technical Notes are available only from the Office of Technical Services, U.S. Department of Commerce, Washington 25, D.C. (Order by $P B$ number). Reprints from outside journals and the NBS Journal of Research may often be obtained directly from the authors. 